\title{
(Mis) understanding your native language: Regional accent impedes processing of information status
}

\author{
Anja Arnhold ${ }^{1} \cdot$ Vincent Porretta $^{1,2} \cdot$ Aoju Chen ${ }^{3} \cdot$ Saskia A.J.M. Verstegen ${ }^{3} \cdot$ Ivy Mok $^{1} \cdot$ Juhani Järvikivi $^{1}$
}

Published online: 6 May 2020

(C) The Psychonomic Society, Inc. 2020

\begin{abstract}
Native-speaker listeners constantly predict upcoming units of speech as part of language processing, using various cues. However, this process is impeded in second-language listeners, as well as when the speaker has an unfamiliar accent. Whereas previous research has largely concentrated on the pronunciation of individual segments in foreign-accented speech, we show that regional accent impedes higher levels of language processing, making native listeners' processing resemble that of second-language listeners.

In Experiment 1, 42 native speakers of Canadian English followed instructions spoken in British English to move objects on a screen while their eye movements were tracked. Native listeners use prosodic cues to information status to disambiguate between two possible referents, a new and a previously mentioned one, before they have heard the complete word. By contrast, the Canadian participants, similarly to second-language speakers, were not able to make full use of prosodic cues in the way native British listeners do.

In Experiment 2, 19 native speakers of Canadian English rated the British English instructions used in Experiment 1, as well as the same instructions spoken by a Canadian imitating the British English prosody. While information status had no effect for the Canadian imitations, the original stimuli received higher ratings when prosodic realization and information status of the referent matched than for mismatches, suggesting a native-like competence in these offline ratings.

These findings underline the importance of expanding psycholinguistic models of second language/dialect processing and representation to include both prosody and regional variation.
\end{abstract}

Keywords Language comprehension $\cdot$ Accent $\cdot$ Dialect $\cdot$ Intonation

\section{Introduction}

Whether we call a tomato "tomahto" or "tomayto" has come to represent an unimportant or minor difference - "it's all the same

Electronic supplementary material The online version of this article (https://doi.org/10.3758/s13423-020-01731-w) contains supplementary material, which is available to authorized users.

Anja Arnhold

arnhold@ualberta.ca

1 Department of Linguistics, University of Alberta, 4-32 Assiniboia Hall, Edmonton, Alberta T6G2E7, Canada

2 Department of Psychology, University of Windsor, Windsor, Ontario, Canada

3 Utrecht Institute of Linguistics, Utrecht University, Utrecht, The Netherlands to me," as the saying goes. However, what importance such socio-linguistic differences actually have for language processing, and how to integrate their potential effects in psycholinguistic models, is far from clear. On the one hand, recent research shows that regional accents different from the listeners', such as Indian English for Canadian listeners, impede word processing (e.g., Floccia, Butler, Goslin, \& Ellis, 2009; Hawthorne, Järvikivi, \& Tucker, 2018). Much the same way that processing sounds, words, and sentences in foreignaccented speech can be more effortful and error prone than in one's native (or familiar) accent, an unfamiliar regional accent can impede predictive processes during language comprehension (Grey \& van Hell, 2017; Hanulíková, van Alphen, van Goch, \& Weber, 2012; Hanulíková \& Weber, 2012; Porretta, Buchanan, \& Järvikivi, 2020; Porretta, Tucker, \& Järvikivi, 2016; Romero-Rivas, Martin, \& Costa, 2016). On the other hand, several studies treat regional accents as a type of phonetic variation similar to speaker variation within a regional accent. 
For example, Le, Best, Tyler, and Kroos (2007) used regional variants to ask how much phonetic detail is represented in the mental lexicon, comparing psycholinguistic models assuming abstract phonological representations of words (Cohort model - Marslen-Wilson, 1987; TRACE - McClelland \& Elman, 1986) against models assuming storage of phonetic details (episodic theory - Goldinger, 1998; exemplar theory - Johnson, 1997). They tested spoken-word recognition of stimuli in either the participants' native dialect or in one of two unfamiliar nonnative dialects, one of which was phonetically more similar to the native accent than the other. Based on their finding of higher accuracy and earlier recognition in the phonetically similar unfamiliar dialect, Le et al. argued that mental representations must contain both abstract representations and fine phonetic detail. Crucially, this and other studies assume that dialect differences are a kind of phonetic variant that listeners map to their existing representations or add to their existing set of exemplars (Best, Tyler, Gooding, Orlando, \& Quann, 2009; Kraljic, Brennan, \& Samuel, 2008, b; Nycz, 2013). Thus, they suggest that different dialects share the same mental representations, i.e. that "tomahto" or "tomayto" are underlyingly the same.

Yet, these and other studies on the processing of accented speech typically concentrate on the divergent pronunciation of individual segments or the transfer of syllable structure, and ignore higher levels of language processing, including speech prosody (see overview in Cristia et al., 2012). However, prosody has a wide range of crucial functions in transmitting sentence- and discourse-level information, like marking distinctions between questions, statements, and commands, or highlighting new information, which are realized differently in different languages (Jun, 2005, 2014; Kügler \& Calhoun, in press), as well as differing between regional varieties of the same language (e.g., Fletcher, Grabe, \& Warren, 2005, on English; Frota et al., 2015, on Portuguese). In the current study, we aimed to find out whether regional accent can impede language processing at the discourse level by investigating Canadian English listeners' use of prosodic cues to identify new versus previously mentioned referents when processing British-accented English.

Research shows that when listeners process complex referring expressions, they incrementally use information from each word to reduce the set of possible referents to the intended one (Altmann \& Kamide, 1999, 2007; Eberhard, Spivey-Knowlton, Sedivy \& Tanenhaus, 1995; Kamide, Scheepers, \& Altmann, 2003; Sedivy, Tanenhaus, Chambers, \& Carlson 1999). Among other cues, listeners exploit prosodic information to predict upcoming referents. For example, when listeners move objects, following instructions such as "Put the candle above the diamond. Now put the candle/CANDY below the triangle," they quickly use prosodic prominence (candle/
CANDY) to predict which object needs to be moved next. Indeed, even though candle and candy are segmentally identical up until the last phoneme, listeners do not wait until the segmental disambiguation point. Instead, they can and typically do predict the referent based on the prosodic marking of its information status: An accent on the first syllable, $C A N$, points to the new referent candy while an unaccented can already elicits a significant increase in looks to the given referent candle (Dahan, Tanenhaus, \& Chambers, 2002). If this prediction is not borne out (i.e. $C A N$ in the given candle and can in the new candy), a significant delay in finding the correct object is incurred. Using this same experimental paradigm, Chen, den Os, and de Ruiter (2007) found that native speakers of British English were sensitive not only to the placement of the accent but also to the shape of the accent (i.e., accent type). Native British listeners associated falling accents with new referents and rising accents and no accent with given referents. However, even advanced Dutch learners of English did not behave in a native-like manner in an experiment using the same design and stimuli (Chen \& Lai, 2011).

Here, we investigate the extent to which Canadian listeners' reactions to British English prosodic cues to information status resemble those of British native and Dutch secondlanguage speakers of English. We first investigate Canadian listeners' online processing with an eye-tracking study. A second experiment more explicitly addresses the issue of shared versus different representations for different dialects by testing if the same prosodic cues are rated as equally contextually appropriate when produced by a Canadian speaker.

\section{Experiment 1: Eye-tracking study}

\section{Participants}

We recruited 55 self-identified native English speakers, all of whom were students at the University of Alberta at the time of testing. Data from 13 speakers were discarded due to the following reasons: poor calibration or tracking $(n=7)$, having grown up in an English-speaking country other than Canada $(n=3)$, starting to learn English after the age of 4 years $(n=2)$, and having lived in a non-English-speaking country for several years during childhood and adolescence $(n=1)$. Thus, we analyzed data from 42 participants ( 26 female, 13 male, three not indicated; mean age: 19.6 years). The study was approved by the Research Ethics Board 2 of the University of Alberta.

\section{Materials and procedure}

We used the visual and auditory stimuli from Chen et al. (2007) and Chen and Lai (2011), who adopted the design 
and items from Dahan et al. (2002). The target items were made up of 18 cohort target-competitor pairs that had similar frequencies and shared an initial phoneme string of various

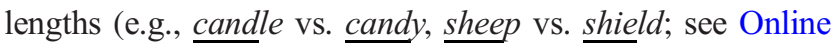
Supplementary Materials for details).

Participants saw a $5 \times 5$ grid containing pictures of four objects (target, competitor, and two distractors), as well as four geometrical shapes. Following aurally presented instructions spoken in Standard Southern British English, they used a computer mouse to click on and move the objects, which differed between trials, relative to the geometrical shapes, which remained constant across the entire experiment. Within each trial, participants followed two instructions (Table 1), while their eye movements were tracked with an EyeLink 1000 eye-tracker. The second instruction always required moving the target, while the first one required either moving the target or the competitor. This manipulated the information status of the target in the second instruction: When the target had already been mentioned in the first instruction, it was given in the second instruction, but when the first instruction concerned the competitor, the target was new in the second instruction.

Additionally, accentuation of the target word was manipulated in the second instruction, so that the target word carried a falling accent, a rising accent, or was unaccented (see Fig. 1 and Online Supplementary Materials; the first instruction always had the same intonational contour). Information status (given/new) and accentuation (falling/rising/unaccented) of the target word in the second instruction were crossed, yielding six experimental conditions.

\section{Hypothesis and predictions}

If native speakers of Canadian English associate falling accents with newness, but rising accents and unaccented words with givenness, like native speakers of British English do, the following predictions (P1 through P7) can be made: Participants should show more looks to the competitor (P1) when a target with a falling accent is given than when it is new, (P2) when an unaccented target is new than when it is given, (P3) when a target with a rising accent is new than when it is given, (P4) when a given target has a falling accent than when it is unaccented, (P5) when a given target has a falling accent than when it has a rising accent, (P6) when a new target is unaccented than when it has a falling accent,
(P7) when a new target has a rising than when it has a falling accent.

\section{Analysis and results}

As a measure of interference, we analyzed the proportion of looks to the competitor as a time series between $200 \mathrm{~ms}$ and $700 \mathrm{~ms}$ after the onset of the target word as our dependent variable (Fig. 2). Proportions were transformed to empirical logits for statistical analysis. We used generalized additive mixed-effects modelling (GAMM) in R (Porretta, Kyröläinen, van Rij, \& Järvikivi, 2018; R Core Team, 2018; Wood, 2016) to model the time series data (727 trials total) (see Online Supplementary Materials for details on preprocessing and analysis).

Based on statistical modelling, Fig. 3 illustrates the difference in looks to the competitor between all pairs of conditions (one pair per panel). Gray shading marks 99\% confidence intervals and dotted vertical lines indicate the time points that are significantly different between the conditions (i.e., where the confidence intervals do not overlap with the line indicating a difference of zero).

As seen in Panel A, for the first $217 \mathrm{~ms}$ of the analysis window, falling accents resulted in more looks to the competitor when the target was given as compared to new, indicating that participants associated falls with newness, supporting P1. Unaccented targets lead to fewer looks to the competitor later in the analysis window $(437-680 \mathrm{~ms})$ when the target was given than when it was new, i.e., participants treated unaccented realizations as a cue to givenness (Panel B, P2). Panel C illustrates that for new targets, there were more looks to the competitor for rising accents than falling within a period of $91 \mathrm{~ms}$ (316-407 ms), in line with falling accents being a stronger cue to newness than rising ones (P7). For rising accents (Panel D), a significant difference between given and new targets appeared at the very beginning of the analysis window. The effect was brief $(30 \mathrm{~ms})$ and opposite to the prediction in $\mathrm{P} 3$, i.e., more competitor looks for given rises than for new ones (see Online Supplementary Materials for discussion). Lastly, none of the other differences between conditions (panels E through I) reached significance.

In sum, participants treated falling accents as more appropriate for new than for given targets and unaccented targets as more appropriate when given than when new. Rising accents, though less appropriate for new targets than falls, were not more appropriate for given than for new targets. Thus,

Table 1. Example of spoken two-part instruction during one trial in both information status conditions. Target: candle; competitor: candy

\begin{tabular}{lll}
\hline & Information status: Given & Information status: New \\
\hline Instruction 1 & Put the candle above the diamond & Put the candy above the diamond \\
Instruction 2 & Now put the candle below the triangle & Now put the candle below the triangle \\
\hline
\end{tabular}



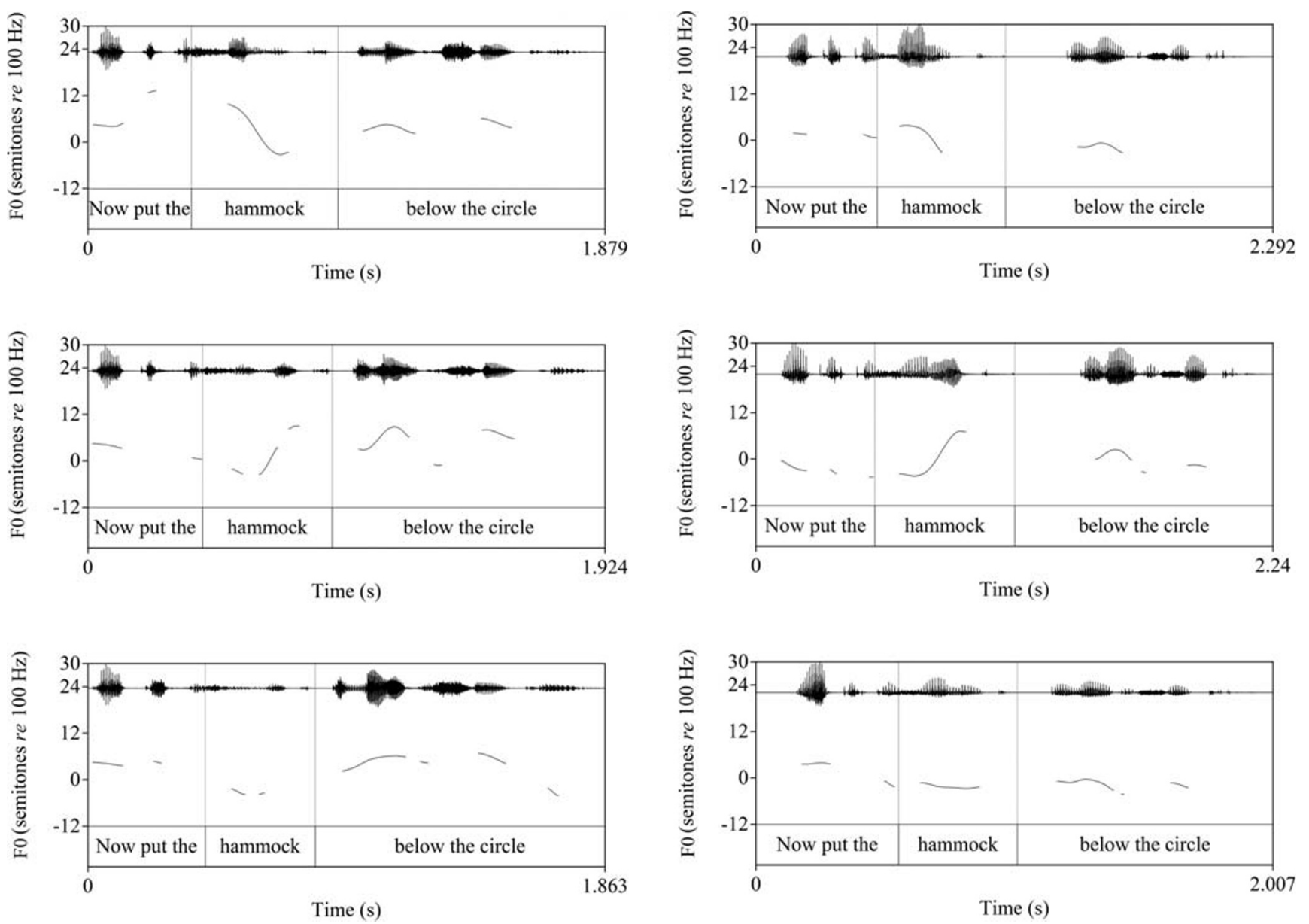

Fig. 1. Example pitch contours for instruction 2 for target word hammock in the three accentuations: falling accent (top panel), rising accent (middle panel), and unaccented (bottom panel) and for both speaker accents, Standard Southern British (left) and produced by a speaker of

Canadian English speakers' reaction to these stimuli differed from that of British English speakers, who clearly associated rising accents with givenness (Chen et al., 2007), contradicting our hypothesis.

\section{Experiment 2: Rating study}

\section{Participants}

Nineteen native speakers of Canadian English participated in the study (13 female, mean age 19.11 years).

\section{Materials and procedure}

Materials were the spoken British English stimuli used in Experiment 1, as well as the same materials spoken by a male native speaker of Canadian English who imitated the prosody of the original British English stimuli (see Fig. 1, Online Supplementary Materials, for details). All participants

Canadian English imitating the prosody of the British English productions (right). Only the British-accented stimuli on the left were used in Experiment 1, while Experiment 2 used stimuli with both regional accents

encountered all items in all conditions in both varieties (18 items $\times 6$ conditions $\times 2$ varieties $=216$ target trials +46 filler trials +2 practice trials), presented in six blocks of 44 stimuli. Each block contained either Canadian or British English stimuli; order within and between blocks was randomized for each participant. In each trial, participants listened to two consecutive instructions and rated the appropriateness of the prosody of the second instruction with respect to the first on a scale from 1 (not appropriate) to 5 (very appropriate).

\section{Hypotheses and predictions}

If native speakers of Canadian English, like native speakers of British English, associated falling accents with new information, but rising accents and unaccented words with givenness, we would predict that they rate falling accents as more appropriate than rising ones and unaccented realizations when targets are new, but rate unaccented and rising as more appropriate than falling accents when targets are given (P1). If both varieties share the same representation in the minds of the 


\section{Competitor looks by condition}

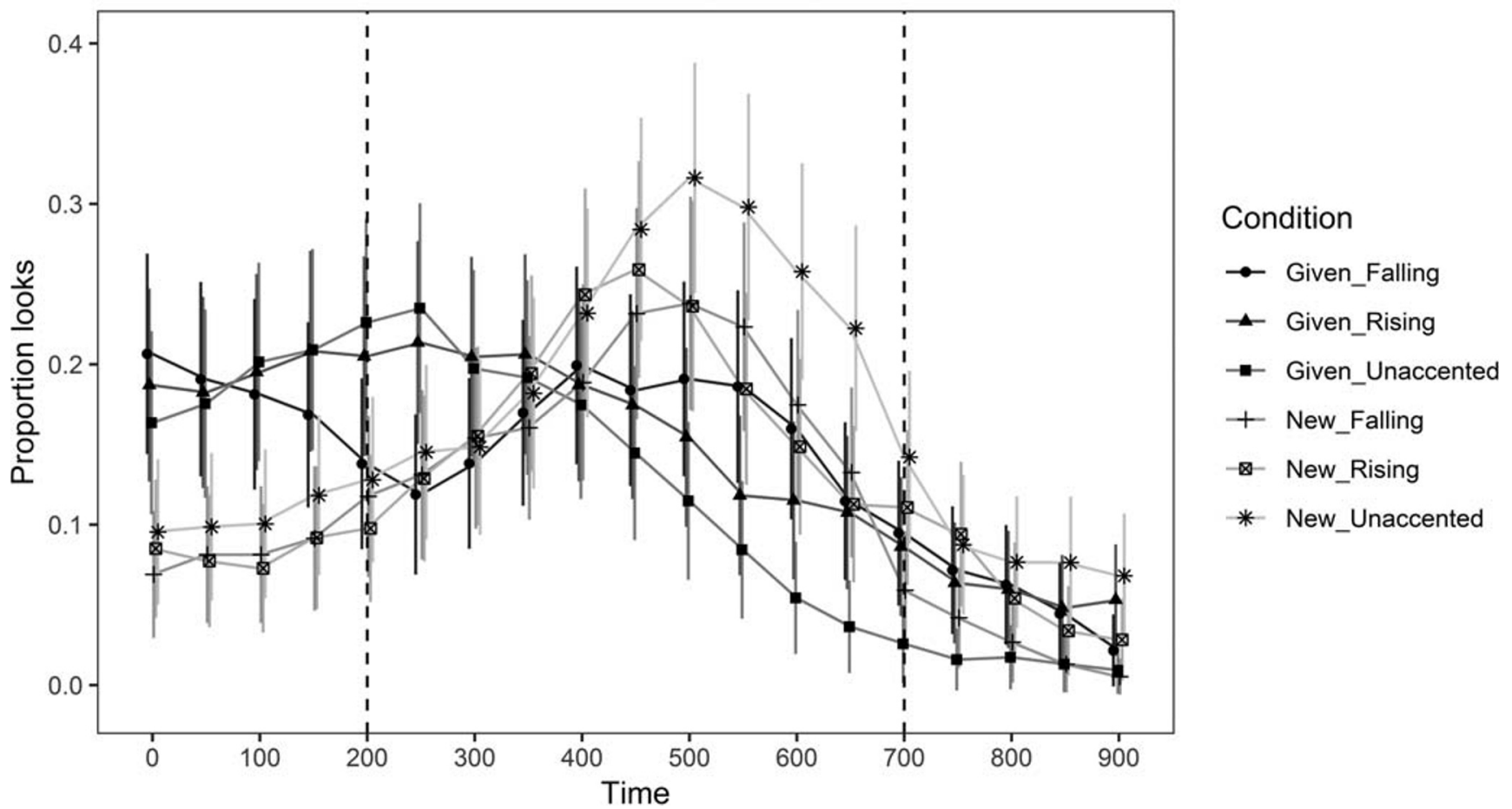

Fig. 2. Average proportion of looks to competitor by experimental condition. Given and new refer to the information status of the target referent in the second instruction of each trial. Error bars represent standard error. Vertical dotted lines indicate the selected analysis window

Canadian speakers, British English and Canadian-spoken stimuli should show no differences in rating (P2).

\section{Analysis and results}

We analyzed participants' ratings $(216 \times 19=4,104$ data points) with GAMMs for ordinal data (Baayen \& Divjak, 2017, see Online Supplementary Materials). Modelling indicated that the information status of the target only affected participants' preferences regarding accentuation for the original British English stimuli. In the new condition, participants rated falling realizations as more appropriate than rising and unaccented realizations, whereas they gave opposite ratings in the given condition, in line with P1. For the Canadian-spoken stimuli, however, falling accents were always rated significantly higher than rising accents and unaccented realizations, both for new targets and for given ones (Fig. 4), contra P1 and P2.

\section{Discussion and conclusion}

Results from Experiment 1 indicate that when processing British English prosodic cues to information status, contrary to our original hypothesis, native Canadian English speakers resemble non-native speakers confronted with the same stimuli (Chen \& Lai, 2011) rather than native British English speakers (Chen et al., 2007). In both experiments, our Canadian participants treated falling accents as a cue to newness and unaccented realizations as a cue to givenness. However, rising accents, which are a clear cue to givenness for native British English speakers, were not a clear cue towards either information status in Experiment 1. In line with this, Canadian listeners showed no effect of information status on the ratings of Canadian-spoken stimuli in Experiment 2. These findings suggest that Canadian English does not use the same prosodic marking of information status as British English. Canadian speakers, while of course native speakers of English, are in that sense non-native speakers of the British variety.

Moreover, our results showed a difference between participants' ability to use British English prosodic cues to information status in rapid online speech processing (Experiment 1) and in offline ratings (Experiment 2). This could suggest that Canadian and British English accentuation patterns receive separate mental representations, which are not equally accessible. In such a view, Canadian speakers would form new categories for acquired British English accents, distinct from their existing native accent inventory in both form and associated meaning and function. Alternatively, both patterns could share a representation, so that processing a non- 
A: Falling_Given - Falling_New

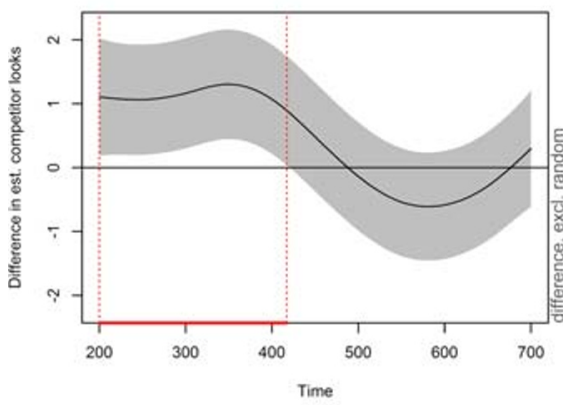

D: Rising_Given - Rising_New

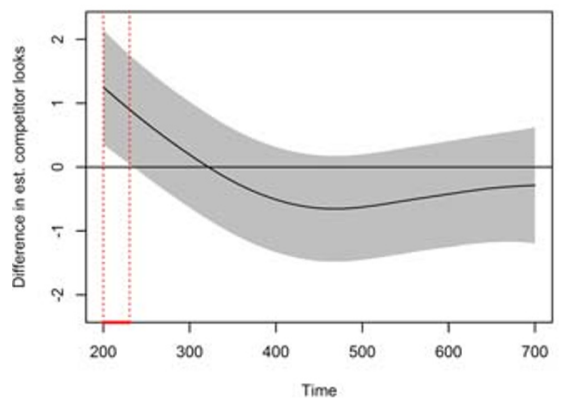

G: Unaccented_New - Rising_New

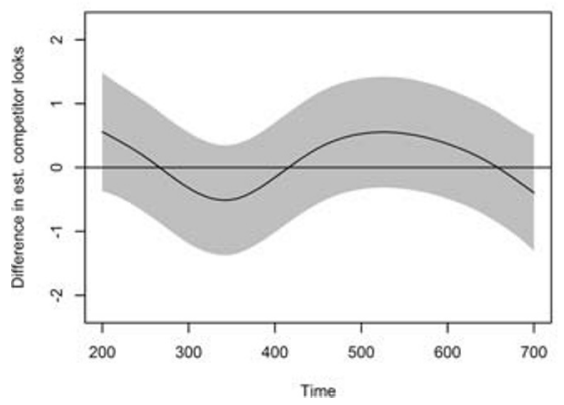

B: Unaccented_Given - Unaccented_New

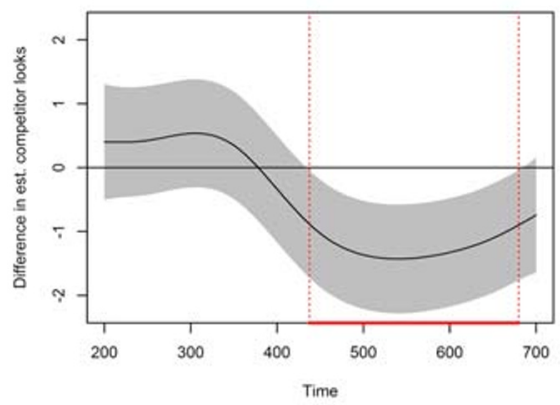

E: Unaccented_Given - Falling_Given

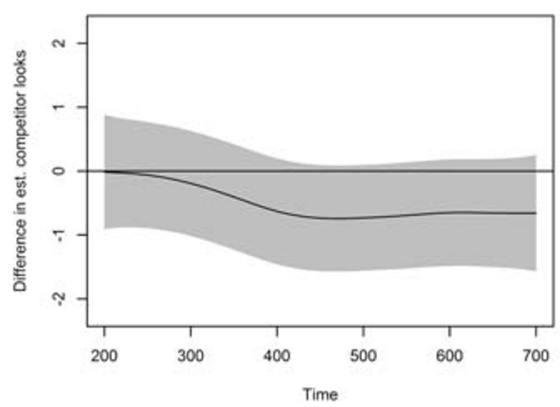

H: Unaccented_New - Falling_Now

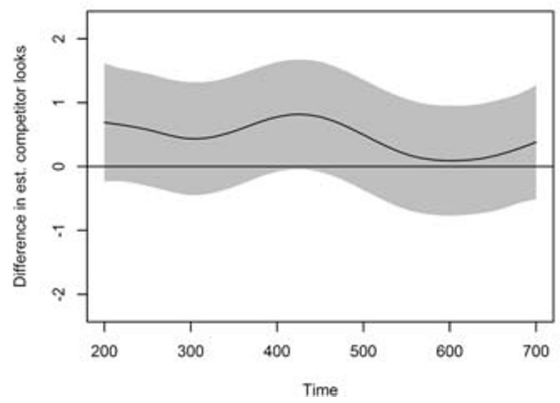

C: Rising_New - Falling_New

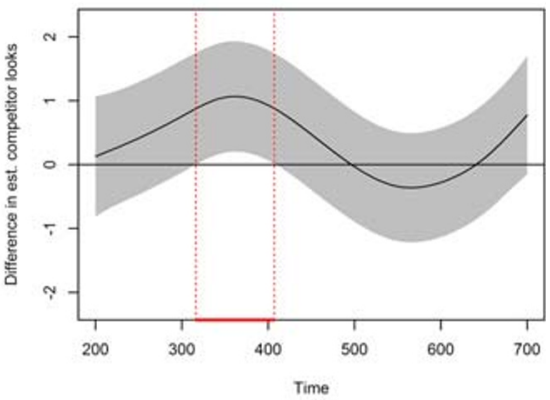

F: Rising_Given - Falling_Given

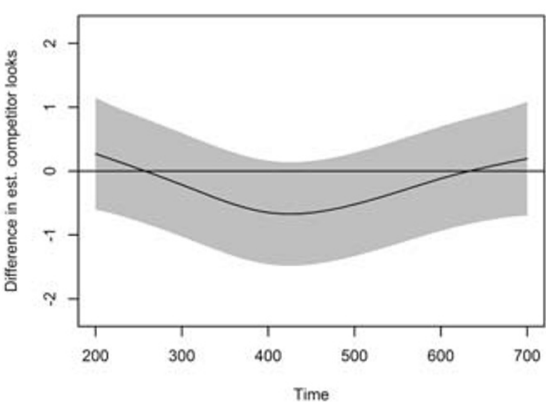

I: Unaccented_Given - Rising_Given

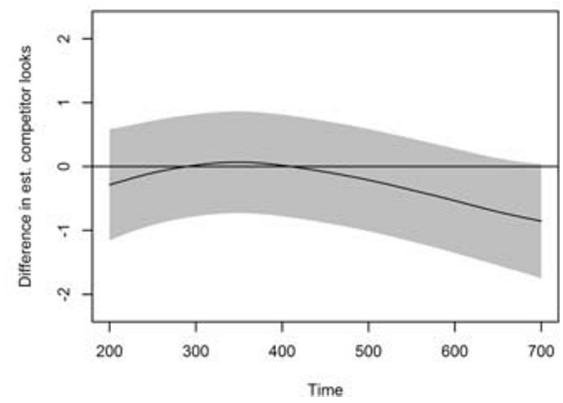

Fig. 3. Difference curves for all pairs of experimental conditions. Shading marks $99 \%$ confidence intervals, vertical dotted lines highlight significant differences

native dialect entails mapping a less familiar surface variant of an accent to the existing underlying form, which is already associated with a pragmatic meaning (e.g., signaling an information status like givenness). This mapping may be more or less feasible depending on the time constraints and demands imposed by the task (in addition to other factors like previous exposure to the dialect). Separate representations are suggested by Sumner and Samuel (2009) for New York City natives who produced "r-dropping" variants of works like baker and filter, but also showed priming for General American pronunciations without "r-dropping." For a second group, who showed semantic priming with " $r$ dropping," but did not produce it in their own speech, they suggest the second alternative, a single underlying representation (also see references in the Introduction). For our participants, results of Experiment 2 seem to support the first alternative: Canadian listeners' ratings of the original British stimuli indicated an association between accentuation and information status similar to native speakers of British English, but their ratings of the Canadian-spoken stimuli did not display that same association. This might suggest that Canadian listeners drew on two distinct mappings between prosodic form and meaning/function to assess the Canadian-spoken versus original British stimuli.

Ultimately, the present results demonstrate that it is possible and necessary for the relatively small fields of research on the acquisition of regional dialects (Nycz, 2013) and processing differences between languages versus dialects (Melinger, 2018) to expand to also consider prosody. They also suggest the need to adapt psycholinguistic models that have overwhelmingly been developed for words and phonemes in research on second language (L2) processing (Keatley, 1992; 


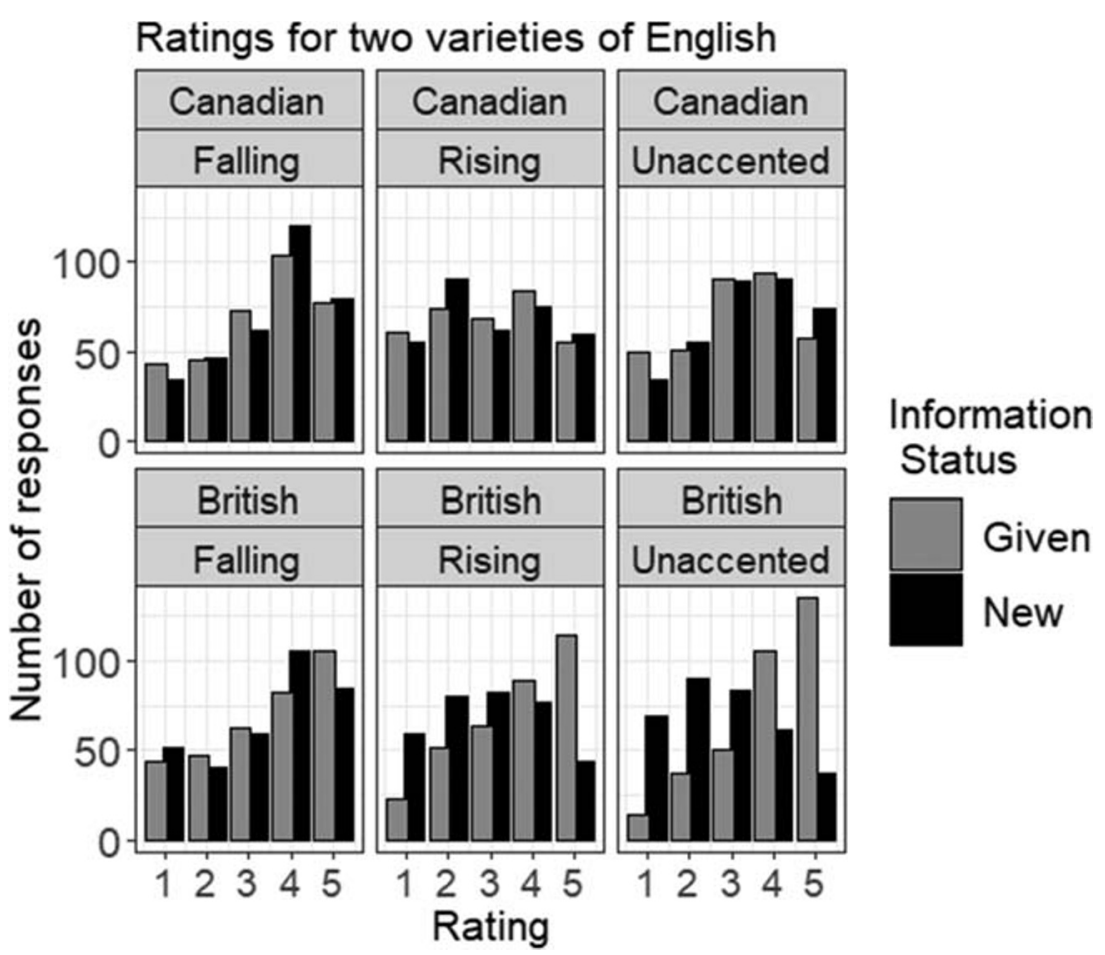

Fig. 4. Ratings of appropriateness of accentuation by information status for two English varieties ( $1=$ not appropriate, $5=$ very appropriate)

Segalowitz \& Trofimovich, 2012), L2 phonology (Eckman, 2012), and L2 acquisition (Faris, Best, \& Tyler, 2018; Flege \& MacKay, 2004) to include prosody. Some remarks appear in de Bot (1992), who suggests that L2 speakers likely do not have two separate prosodic systems, since pronunciation is often influenced by the first language even in highly proficient L2 speakers. If further research supports our tentative suggestion that speakers do in fact establish a second system when acquiring a second language or dialect (also see Sumner \& Samuel, 2009), much more work is needed to model this process and the resulting two prosodic representations. Crucially, our participants' performance when processing a regional variety of their native language shows that dialect differences in the mind of listeners concern not only segments but also prosody, not only word meanings but also the transmission of discourse-level distinctions like information status - qualitatively different aspects that should be reflected in psycholinguistic modelling. Thus, these dialect differences go far beyond the difference between "tomayto" and "tomahto."

Acknowledgements We thank Maeghan Jerry for help in stimulus preparation and Ran Yi, Chao (Jacob) Lang (郎超), and Devon Gozjolko for help with running participants. We thank two anonymous reviewers for comments on the first version of this manuscript.

This research was supported by a Social Sciences and Humanities Research Council of Canada (http://www.sshrc-crsh.gc.ca/) Partnership Grant (Words in the World, 895-2016-1008).

Open Practices Statement The data and materials for all experiments are available upon request. The experiments were not preregistered.

\section{References}

Altmann, G. T., \& Kamide, Y. (1999). Incremental interpretation at verbs: restricting the domain of subsequent reference. Cognition, 73(3), 247-64. https://doi.org/10.1016/S0010-0277(99)00059-1

Altmann, G. T. M., \& Kamide, Y. (2007). The real-time mediation of visual attention by language and world knowledge: Linking anticipatory (and other) eye movements to linguistic processing. Journal of Memory and Language, 57(4), 502-518. https://doi.org/10.1016/ j.jml.2006.12.004

Bayen, R. H., \& Divjak, D. (2017). Ordinal GAMMs: A New Window on Human Ratings. In A. Makarova, S. M. Dickey, \& D. Divjak (Eds.), Each Venture a New Beginning. Studies in Honor of Laura A. Janda (pp. 39-56). Bloomington: Slavica.

Best, C. T., Tyler, M. D., Gooding, T. N., Orlando, C. B., \& Quann, C. A. (2009). Development of phonological constancy: Toddlers' perception of native- and Jamaican-accented words. Psychological Science, 20(5), 539-542. https://doi.org/10.1111/j.1467-9280.2009. 02327. $\mathrm{x}$

Chen, A., den Os, E., \& de Ruiter, J. P. (2007). Pitch accent type matters for online processing of information status: Evidence from natural and synthetic speech. Linguistic Review, 24(2-3), 317-344. https:// doi.org/10.1515/TLR.2007.012

Chen, A., \& Lai, V. (2011). Comb or coat: The role of intonation in online reference resolution in a second language. In W. Zonneveld, $\mathrm{H}$. Quené, \& W. Heeren (Eds.), Sound and Sounds. Studies presented to M.E.H. (Bert) Schouten on the occasion of his 65th birthday (pp. 57-68). Utrecht: UiL OTS.

Cristia, A., Seidl, A., Vaughn, C., Schmale, R., Bradlow, A., \& Floccia, C. (2012). Linguistic processing of accented speech across the lifespan. Frontiers in Psychology, 3(NOV), 1-15. https://doi.org/10.3389/ fpsyg.2012.00479

Dahan, D., Tanenhaus, M. K., \& Chambers, C. G. (2002). Accent and reference resolution in spoken-language comprehension. Journal of 
Memory and Language, 47(2), 292-314. https://doi.org/10.1016/ S0749-596X(02)00001-3

de Bot, K. (1992). A bilingual production model: Levelt's "speaking" model adapted. Applied Linguistics, 13(1), 1-24. https://doi.org/ 10.1093/applin/13.1.1

Eberhard, K. M., Spivey-Knowlton, M. J., Sedivy, J. C., \& Tanenhaus, M. K. (1995). Eye movements as a window into real-time spoken language comprehension in natural contexts. Journal of Psycholinguistic Research, 24(6), 409-436. https://doi.org/10. 1007/BF02143160

Eckman, F. R. (2012). Second language phonology. In S. M. Gass \& A. Mackey (Eds.), The Routledge Handbook of Second Language Acquisition (pp. 91-105). London / New York: Routledge. https:// doi.org/10.4324/9780203808184.ch6

Faris, M. M., Best, C. T., \& Tyler, M. D. (2018). Discrimination of uncategorised non-native vowel contrasts is modulated by perceived overlap with native phonological categories. Journal of Phonetics, 70, 1-19. https://doi.org/10.1016/j.wocn.2018.05.003

Flege, J. E., \& MacKay, I. R. A. (2004). Perceiving Vowels in a. Studies in Second Language Acquisition, 26, 1-34. https://doi.org/10.1017/ 50272263104261010

Fletcher, J., Grabe, E., \& Warren, P. (2005). Intonational variation in four dialects of English: The high rising tune. In S.-A. Jun (Ed.), Prosodic typology. The phonology of intonation and phrasing (pp. 390-409). Oxford: OUP.

Floccia, C., Butler, J., Goslin, J., \& Ellis, L. (2009). Regional and foreign accent processing in English: Can listeners adapt? Journal of Psycholinguistic Research, 38(4), 379-412. https://doi.org/10. 1007/s10936-008-9097-8

Frota, S., Cruz, M., Svartman, F., Collischon, G., Fonseca, A., Serra, C., ... Vigário, M. (2015). Intonational variation in Portuguese. In S. Frota \& P. Prieto (Eds.), Intonation in Romance (pp. 235-283). Oxford: OUP. https://doi.org/10.1093/acprof:oso/9780199685332.003.0007

Goldinger, S.D. (1998). Echoes of echoes?: An episodic theory of lexical access. Psychological Review, 105, 251-279. https://doi.org/10. 1037/0033-295X.105.2.251

Grey, S., \& van Hell, J. G. (2017). Foreign-accented speaker identity affects neural correlates of language comprehension. Journal of Neurolinguistics, 42, 93-108. https://doi.org/10.1016/j.jneuroling. 2016.12.001

Hanulíková, A., van Alphen, P. M., van Goch, M. M., \& Weber, A. (2012). When one person's mistake is another's standard usage: The effect of foreign accent on syntactic processing. Journal of Cognitive Neuroscience, 24(4), 878-887. https://doi.org/10.1162/ jocn_a_00103

Hanulíková, A., \& Weber, A. (2012). Sink positive: Linguistic experience with th substitutions influences nonnative word recognition. Attention, Perception, \& Psychophysics, 74(3), 613-629. https:// doi.org/10.3758/s13414-011-0259-7

Hawthorne, K., Järvikivi, J., \& Tucker, B. V. (2018). Finding word boundaries in Indian English-accented speech. Journal of Phonetics, 66, 145-160. https://doi.org/10.1016/j.wocn.2017.09.008

Johnson, K. (1997). Speech perception without speaker normalization. In K. Johnson \& J.W. Mullennix (Eds.) Talker variability in speech processing (pp. 145-166). San Diego: Academic Press.

Jun, S.-A. (Ed.). (2005). Prosodic typology: The phonology of intonation and phrasing. https://doi.org/10.1093/acprof:oso/9780199249633. 001.0001

Jun, S.-A. (Ed.). (2014). Prosodic typology II. The phonology of intonation and phrasing. Oxford: OUP. https://doi.org/10.1093/acprof:oso/ 9780199567300.001.0001

Kamide, Y., Scheepers, C., \& Altmann, G. T. M. (2003). Integration of syntactic and semantic information in predictive processing: Crosslinguistic evidence from German and English. Journal of Psycholinguistic Research, 32(1), 37-55. https://oi.org/10.1023/ A:1021933015362
Keatley, C. W. (1992). History of Bilingualism Research in Cognitive Psychology. In R. J. Harris (Ed.), Cognitive Processing in Bilinguals (pp. 15-49). Amsterdam: Elsevier. https://doi.org/10. 1016/S0166-4115(08)61486-7

Kraljic, T., Brennan, S. E., \& Samuel, A. G. (2008). Accommodating variation: Dialects, idiolects, and speech processing. Cognition, 107(1), 54-81. https://doi.org/10.1016/j.cognition.2007.07.013

Kügler, F., \& Calhoun, S. (in press). Typology of prosodic encoding of information structure. In C. Gussenhoven \& A. Chen (Eds.), The Oxford Handbook of Language Prosody. Oxford: OUP.

Le, J. T., Best, C. T., Tyler, M. D., \& Kroos, C. (2007). Effects of nonnative dialects on spoken word recognition. Proceedings of the Annual Conference of the International Speech Communication Association, INTERSPEECH, 2, 1417-1420.

Marslen-Wilson, W.D. (1987). Functional parallelism in spoken wordrecognition. Cognition, 25, 71-102. https://doi.org/10.1016/00100277(87)90005-9

McClelland, J.L., \& Elman, J.L. (1986). The TRACE model of speech perception. Cognitive Psychology, 18, 1-86. https://doi.org/10.1016/ 0010-0285(86)90015-0

Melinger, A. (2018). Distinguishing languages from dialects: A litmus test using the picture-word interference task. Cognition, 172, 73-88. https://doi.org/10.1016/j.cognition.2017.12.006

Nycz, J. (2013). Changing words or changing rules? Second dialect acquisition and phonological representation. Journal of Pragmatics, 52, 49-62. https://doi.org/10.1016/j.pragma.2012.12.014

Porretta, V., Buchanan, L., \& Järvikivi, J. (2020). When processing costs impact predictive processing: The case of foreign-accented speech and accent experience. Attention, Perception, \& Psychophysics https://doi.org/10.3758/s13414-019-01946-7

Porretta, V., Kyröläinen, A., van Rij, J., \& Järvikivi, J. (2018). Visual world paradigm data: From preprocessing to nonlinear time-course analysis. In I. Czarnowski, R. J. Howlett, \& L. C. Jain (Eds.), Intelligent Decision Technologies 2017. Smart Innovation, Systems and Technologies 73 (pp. 268-277). Cham: Springer International.

Porretta, V., Tucker, B. V., \& Järvikivi, J. (2016). The influence of gradient foreign accentedness and listener experience on word recognition. Journal of Phonetics, 58, 1-21. https://doi.org/10.1016/j.wocn. 2016.05.006

R Core Team. (2018). R: A Language and Environment for Statistical Computing. Vienna, Austria: R Foundation for Statistical Computing. Retrieved from https://www.r-project.org/

Romero-Rivas, C., Martin, C. D., \& Costa, A. (2016). Foreign-accented speech modulates linguistic anticipatory processes. Neuropsychologia, 85, 245-255. https://doi.org/10.1016/j. neuropsychologia.2016.03.022

Sedivy, J. C., K. Tanenhaus, M., Chambers, C. G., \& Carlson, G. N. (1999). Achieving incremental semantic interpretation through contextual representation. Cognition, 71(2), 109-147. https://doi.org/ 10.1016/S0010-0277(99)00025-6

Segalowitz, N., \& Trofimovich, P. (2012). Second language processing. In S. M. Gass \& A. Mackey (Eds.), The Routledge Handbook of Second Language Acquisition (pp. 179-192). London / New York: Routledge.

Sumner, M., \& Samuel, A. G. (2009). The effect of experience on the perception and representation of dialect variants. Journal of Memory and Language, 60(4), 487-501. https://doi.org/10.1016/j.jml.2009. 01.001

Wood, S. N. (2016). mgcv: Mixed GAM computation vehicle with GCV/ AIC/REML smoothness estimation. R package version 1.8-23.

Publisher's note Springer Nature remains neutral with regard to jurisdictional claims in published maps and institutional affiliations. 